\title{
ON NONLINEAR VOLTERRA-FREDHOLM TYPE DISCRETE FRACTIONAL SUM INEQUALITIES
}

\author{
SUBHASH KENDRE* AND NAGESH KALE
}

\begin{abstract}
In the current paper, we establish some new forms of the discrete fractional sum inequalities of the Volterra-Fredholm type. These inequalities can serve as a powerful tool in the analysis of boundedness and uniqueness of the solutions of certain Volterra-Fredholm fractional sum-difference equations and their variants. Some applications are also given to convey the importance of our results.
\end{abstract}

Mathematics subject classification (2020): 26D15, 39A12, 26 A33.

Keywords and phrases: Volterra-Fredholm type, discrete fractional sum inequality, fractional sum difference equation, boundedness.

\section{REFERENCES}

[1] B. G. PaChPatte, Inequalities for Finite Difference Equations, Marcel Dekker, Inc., New York, 2002.

[2] Haidong Liu and Fanwei Meng, Some new generalized Volterra-Fredholm type discrete fractional sum inequalities and their applications, Journal of Inequalities and Applications, 2016:213, (2016).

[3] Rui A. C. Ferreira, A Discrete fractional Gronwall Inequality, Proc. of the American Mathematical Society, 140, 5 (2012), 1605-1612.

[4] Bin Zheng, Some New Discrete Fractional Inequalities and their applications in Fractional Difference equations, Journal of Mathematical Inequalities, 9, 3 (2015), 823-839.

[5] QING-HuA MA, Some New nonlinear Volterra-Fredholm-type discrete inequalities and their Applications, Journal of Computational and Applied Mathematics, 216, (2008), 451-466.

[6] Qing-Hua Ma And Wing-Sum Cheung, Some New Nonlinear difference inequalities and their Applications, Journal of Computational and Applied Mathematics, 202, (2007), 339-351.

[7] Run Xu And Xiangting MA, Some new retarded nonlinear Volterra-Fredholm type integral inequalities with maxima in two variables and their applications, Journal of Inequalities and Applications, 2017:187, (2017).

[8] QING-HUA MA, Estimates on some power nonlinear Volterra-Fredholm type discrete inequalities and their applications, Journal of Computational and Applied Mathematics, 233, (2010), 2170-2180.

[9] L. OU-IANG, The boundedness of solutions of linear differential equations $y^{\prime \prime}+A(t) y^{\prime}=0$, Advances in Mathematics, 3, (1957), 409-415.

[10] E. H. YANG, On some nonlinear integral and discrete inequalities related to Ou-Iang's inequality, Acta Mathematica Sinica, 14, 3 (1998), 353-360.

[11] W. S. CheunG AND Q. H. MA, On certain new Gronwall-Ou-Iang type integral inequalities in two variables and their applications, Journal of Inequalities and Applications, 2005, 4 (2005), 347-361.

[12] F. M. Atici And S. SEngul, Modelling with fractional difference equations, Journal of Math. Anal. Appl., 369, (2010), 1-9.

[13] F. M. Atici And P. W. EloE, A transform method in discrete fractional calculus, Int. Journal of Diff. eqn., 2, 2 (2007), 165-176.

[14] F. M. Atici AND P. W. Eloe, Initial value problems in discrete fractional calculus, Proc. of the American Mathematical Society, 137, 3 (2009), 981-989.

[15] F. M. ATICI AND P. W. Eloe, Gronwall's inequality on discrete fractional calculus, Computers and Mathematics with Applications, 64, 10 (2012), 3193-3200. 
[16] Walter G. Kelley and Allan C. Peterson, Difference Equations- An Introduction with Applications, Academic Press, New York, (2002).

[17] M. HoLm, Sum and difference compositions in discrete fractional calculus, CUBO A Mathematical Journal, 13, 3 (2011), 153-184.

[18] P. O. Mohammed, A generalized uncertain fractional forward difference equations of RiemannLiouville type, Journal of Mathematics Research, 11, 4 (2019), 43-50.

[19] Thabet Abdeljawad, On Riemann and Caputo fractional differences, Computers and Mathematics with Applications, 62.3, (2011), 1602-1611.

[20] Thabet Abdeljawad, On Delta and Nabla Caputo Fractional Differences and Dual Identities, Discrete Dynamics in Nature and Society, Hindawi Publishing Corporation, 2013, Article ID 406910, (2013).

[21] P. O. Mohammed, Thabet Abdeljawad, F. Jarad and Yu-Ming Chu, Existence and Uniqueness of Uncertain Fractional Backward Difference Equations of Riemann-Liouville type, Mathematical Problems in Engineering, Article ID 6598682, (2020).

[22] M. A. Alqudah, P. O. Mohammed and Thabet Abdeljawad, Solution of Singular Integral Equations via Riemann-Liouville Fractional Integrals, Mathematical Problems in Engineering, Article ID $1250970,(2020)$.

[23] Thabet Abdeljawad, Dual identities in fractional difference calculus within Riemann, Advances in Difference Equations, 2013:36, (2013).

[24] K. S. Miller And B. Ross, Fractional Difference Calculus, Proceedings of the International Symposium on Univalent Functions, Fractional Calculus and their Applications, Nihon University, Koriyama, Japan, (1988), 139-152.

[25] K. Oldham And J. Spanier, The Fractional Calculus: Theory and Applications of Differentiation and Integration to Arbitrary Order, Dover Publications, Inc., Mincola, New York, (2002).

[26] J. B. Diaz And T. J. Olser, Differences of Fractional order, Mathematics of Computation, 28, (1974).

[27] H. Gray and N. Zhang, On a New Definition of the Fractional Difference, Mathematics of Computation, 50, (1988), 513-529.

[28] Igor Podlubny, Fractional Differential Equations, Academic Press, New York, (1999). 